\title{
Training the physician-scientist: views from program directors and aspiring young investigators
}

Christopher S. Williams, ${ }^{1}$ Audra N. Iness, ${ }^{2}$ Rebecca M. Baron, ${ }^{3}$ Olujimi A. Ajijola, ${ }^{4}$ Patrick J. Hu, ${ }^{1}$ Jatin M. Vyas, ${ }^{5}$ Robert Baiocchi, ${ }^{6}$ Alexander J. Adami, Jeremie M. Lever, ${ }^{8}$ Peter S. Klein, ${ }^{9}$ Linda Demer, ${ }^{4}$ Michael Madaio, ${ }^{10}$ Mark Geraci, ${ }^{11}$ Lawrence F. Brass, ${ }^{9}$ Melvin Blanchard, ${ }^{12}$ Robert Salata, ${ }^{13}$ and Mone Zaidi ${ }^{14}$

'Department of Medicine, Vanderbilt University School of Medicine, Nashville, Tennessee, USA. ${ }^{2}$ MD/PhD Program, School of Medicine, Virginia Commonwealth University, Richmond, Virginia, USA. ${ }^{3}$ Department of Medicine, Brigham and Women's Hospital, Harvard Medical School, Boston, Massachusetts, USA. ${ }^{4}$ Department of Medicine, David Geffen School of Medicine at UCLA, Los Angeles, California, USA. ${ }^{5}$ Department of Medicine, Massachusetts General Hospital, Harvard Medical School, Boston, Massachusetts, USA. ${ }^{6}$ Department of Medicine, The Ohio State University College of Medicine, Columbus, Ohio, USA. ${ }^{7} \mathrm{MD} / \mathrm{PhD}$ Program, University of Connecticut School of Medicine, Farmington, Connecticut, USA. ${ }^{8} \mathrm{MD} /$ PhD Program, University of Alabama at Birmingham, Birmingham, Alabama, USA. ${ }^{9}$ Department of Medicine, Perelman School of Medicine, University of Pennsylvania, Philadelphia, Pennsylvania, USA. ${ }^{10}$ Department of Medicine, Medical College of Georgia at Augusta University, Augusta, Georgia, USA. "Department of Medicine, University of Indiana School of Medicine, Indianapolis, Indiana, USA. ${ }^{2}$ Department of Medicine, Washington University School of Medicine, St. Louis, Missouri, USA. ${ }^{13}$ Department of Medicine, Case Western Reserve University, Cleveland, Ohio, USA. ${ }^{14}$ Department of Medicine, Icahn School of Medicine at Mount Sinai, New York, New York, USA.

Conflict of interest: LFB reports research support from DeuteRx and Janssen Research and Development. In addition, he holds two issued patents related to protease-activated receptors. MZ reports that he has consulted or spoken for Amgen, Shire, Alexion, Novartis, Merck, and Roche over the past 5 years. He also consults for Guidepoint, Coleman, and GLC financial houses. Mount Sinai holds one issued and two pending patents on follicle-stimulating hormone, bone mass, and body composition, which if commercialized, would yield income that will be shared with MZ.

Published: December 6, 2018

\section{Reference information:} JCI Insight. 2018;3(23):e125651. https://doi.org/10.1172/jici. insight.125651.
$\mathbf{T}$ here is growing concern that the physician-scientist is endangered due to a leaky training pipeline and prolonged time to scientific independence (1). The NIH Physician-Scientist Workforce Working Group has concluded that as many as 1,000 individuals will need to enter the pipeline each year to sustain the workforce (2). Moreover, surveys of postgraduate training programs document considerable variability in disposition and infrastructure (3). Programs can be broadly grouped into two classes: physician-scientist training programs (PSTPs) that span residency and fellowship training, and research-in-residency programs (RiRs), which are limited to residency but trainees are able to match into PSTPs upon transitioning to fellowship (Figure 1). Funding sources for RiRs and PSTPs are varied and include NIH KL2 and T32 awards, charitable foundations, philanthropy, and institutional support. Furthermore, standards for research training and tools for evaluating programmatic success are lacking. Here, we share consensus generated from iterative workshops hosted by the Alliance of Academic Internal Medicine (AAIM) and the student-led American Physician Scientists Association (APSA).

\section{AAIM-sponsored PSTP and RiR directors workshops}

A 2016 AAIM-sponsored Consensus Conference identified six challenging areas for physician-scientist training, namely curriculum and infrastructure, trainee recruitment, mentorship, funding, tracking outcomes, and continuous improvement (4). Retention and recruitment were also discussed during the Association of Professors of Medicine (APM) meeting, which focused on attracting new talent and creating special career development programs, such as the Harrison Society (Vanderbilt University), Lefkowitz Society (Duke University), Stanbury Service (Massachusetts General Hospital), STAR Program (University of California Los Angeles), and PSTP Scholars (Johns Hopkins University) (5, 6). A second AAIM-sponsored Research Track Program Director's Summit in 2017 provided a summary compilation of best practices for physician-scientist training (Table 1) (7). The 2017 summit was followed by a focused discussion, mainly on funding, mentoring, and retention, at a 2018 AAIM Research Track Directors Workshop.

Several recommendations for funding physician-scientist trainees emerged. At the institutional level, these recommendations include using T32 grants (for fellows), the Clinical and Translational Science Award (CTSA), and the new StARR (R38) and StARRTS (K38) programs, as well as collaborative partnerships with funded groups, clinical revenue streams, philanthropic support, and bridge 


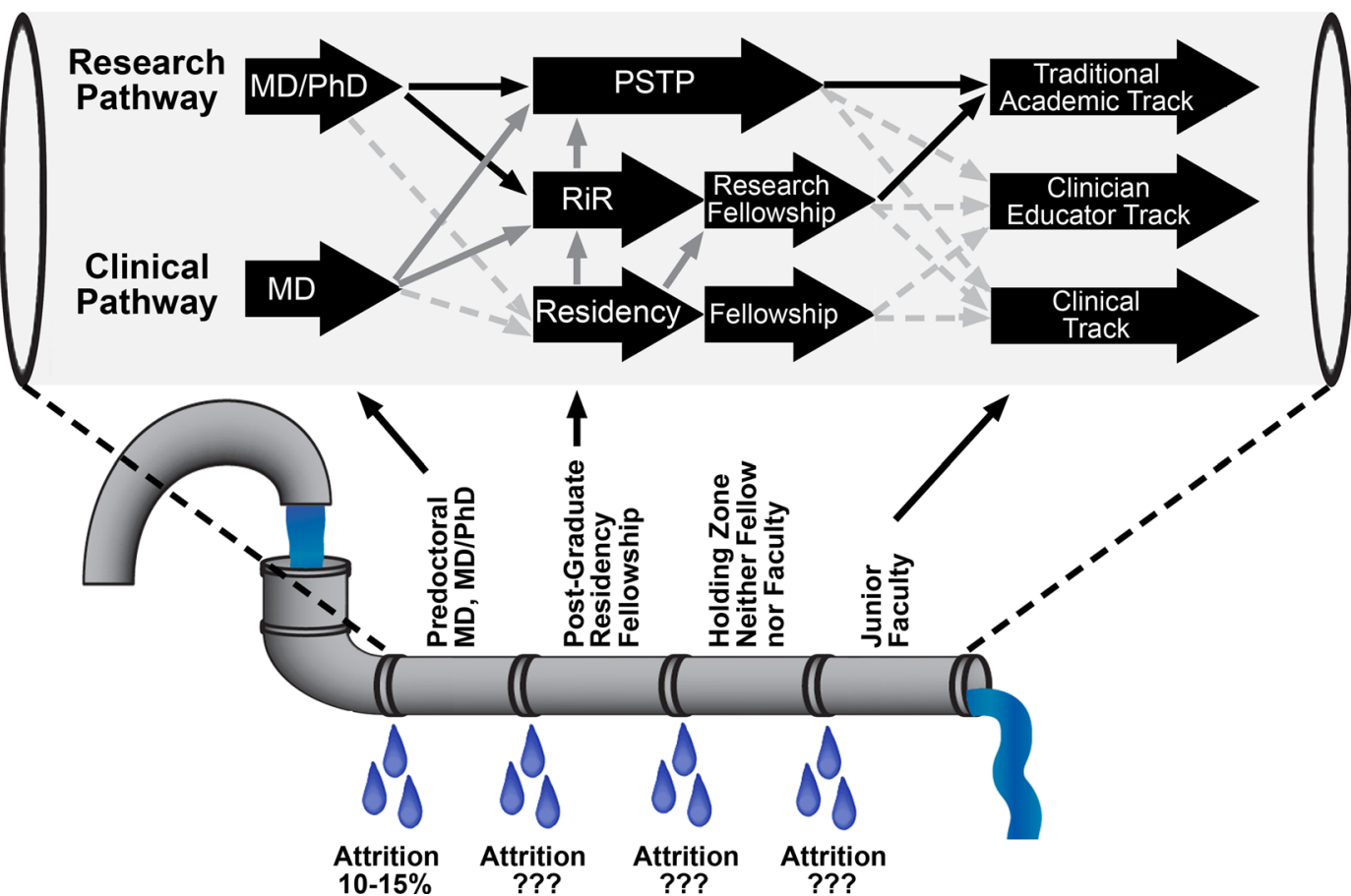

Figure 1. The physician-scientist career path. Representative schematic of the pipeline that yields the physician-scientist workforce and points of attrition, with best known estimates of losses. Also shown are multiple on-ramps for recruitment to this career path. Labeled block arrows represent training opportunities. Arrows indicate options for transitions between training programs, with solid black arrows denoting the standard research-based physician-scientist training pathway, solid gray arrows indicating on-ramps, and dashed gray arrows showing points of pipeline leakiness, where trainees opt not to pursue research-based careers. PSTP: physician-scientist training program; RiR: research in residency. The pipeline was adapted with permission from ref. 1, and the figure was conceptualized in its entirety by AJA and PJH.

funding. In addition to K awards, there was broad enthusiasm for trainees to use the NIH Loan Repayment Program (NLRP), which provides early experience in grant writing and critical debt relief. The NIH NRSA/F32 award was felt to be underutilized; however, feelings were mixed on whether the time spent on this path would detract precious time toward building a competitive resume. Trainees are encouraged to apply for society awards, such as the American Society of Clinical Oncology Young Investigator Award. With that said, inconsistent funding of RiR and PSTP programs was noted as a major contributor to attrition, especially for institutions without access to the listed resources. It also became clear that educational allowances for PSTP trainees are varied, with some institutions providing financial support for travel to national meetings, society membership dues, journal subscriptions, and medical licensing fees. It was noted that direct salary enhancements were rare and, notwithstanding family and childcare needs that older PSTP trainees arriving after $\mathrm{MD} / \mathrm{PhD}$ training may have, higher salaries did not appear to predict success. It was nonetheless agreed that this relatively sensitive area needed thorough and thoughtful appraisal.

Another major outcome was recognition of the value of peer-to-peer and near-peer mentoring. Innovative recommendations included enhanced interactions between RiR/PSTP trainees and their generational counterparts, including $\mathrm{MD} / \mathrm{PhD}$ students, postgraduate fellows, and junior faculty. It was noted that certain institutions host an annual resident-fellow research day that includes $\mathrm{MD} / \mathrm{PhD}$ trainee participation. Certain programs provide travel awards for RiR/PSTP trainees to participate in the Association of American Physicians (AAP), American Society for Clinical Investigation (ASCI), and APSA Joint Meetings, providing an unparalleled opportunity to be identified by department chairs, division directors, and some of the most successful physician-scientist role models.

Finally, there was broad agreement that high priority be placed on developing physician-scientist residents and fellows as junior faculty from within the institution; such a farm team could be a win-win for the trainee, the department, and the institution. It allows a trainee to transition to independence while retaining existing relationships with mentors, who often continue to provide infrastructural support. Departments and 
Table 1. Summary of six emergent areas of physician-scientist training

\begin{tabular}{|c|c|}
\hline Areas of interest & Summary of Recommendations \\
\hline \multirow{3}{*}{$\begin{array}{l}\text { Curriculum and } \\
\text { infrastructure }\end{array}$} & Research opportunities during combined residency and fellowship training \\
\hline & Training in specific areas, including biostatistics, grant writing, and regulatory requirements, among others \\
\hline & Formal alliance and meetings of research track program directors \\
\hline \multirow{3}{*}{ Recruitment and selection } & Significant research experience and a balanced commitment to science and medicine is necessary \\
\hline & Enhancement of diversity as a stated goal \\
\hline & Recruitment of qualified international medical graduates, with additional sources of funding \\
\hline \multirow{3}{*}{$\begin{array}{l}\text { Funding of programs and } \\
\text { trainees }\end{array}$} & Need for strong institutional support \\
\hline & Need for adequate levels of external funding, including career development awards \\
\hline & Funding to support research-track program directors \\
\hline \multirow{2}{*}{$\begin{array}{l}\text { Tracking success of } \\
\text { programs and trainees }\end{array}$} & Requirement for success factors to be tracked purposefully \\
\hline & Need for coordination with other programs and sharing in a national database \\
\hline
\end{tabular}

These areas were highlighted during the 2016 Workshop entitled Re-Examining the Physician-Scientist Workforce: New and Evolving Areas of Research and Pathways to Success in Academic Institutions (4), with the evolution of best practices through the 2017 Research Track Program Directors Summit (7).

divisions would retain and continue to develop someone who is valued and has demonstrated longitudinal commitment to a research-based career. Nonetheless, the temptation for departments to provide lower startup packages for internal recruits should be resisted, so as not to jeopardize careers through under-resourcing. It was also suggested that departments build multiple on-ramps to allow entry to qualified individuals who may have significant research experience, but develop an interest later in their training. Formal strategies to identify, recruit, develop, and support such late bloomers requires considerable development.

\section{APSA Special Workshop}

Considering that $\mathrm{MD} / \mathrm{PhD}$ graduates may use the research track for further training and to examine the generational continuum more purposefully, the APSA Executive Council prepared a set of four questions for RiR and PSTP directors during a special workshop at the AAP/ASCI/APSA Joint Meeting.

Given that I will have already received formal research training in my PhD program, how will the research-track residency further expand my skill set and prepare me for the next phase in my career? Furthermore, what features do RiR or PSTP programs offer beyond traditional clinical fellowships with research time included? It is unusual for an MD/ $\mathrm{PhD}$ graduate to be competitive for a tenure-track faculty position or an NIH K- or R-level award without additional research training prior to transitioning to faculty. PSTP trainees generally need significant protected research time to develop the scientific expertise necessary to sustain long-term success in an investigative career. The Internal Medicine, Pediatrics, Anesthesiology, and Radiology Specialty Boards have thus begun to offer board-compliant research tracks ranging from 6 months to 3 years, and certain Boards have shortened clinical training requirements, typically at the residency stage. Programs also often opt to keep residents engaged in research activities during clinical training. Mentorship is a critical component of PSTPs and facilitates the successful transition to independence for both $\mathrm{MD} / \mathrm{PhD}$ graduates as well as non- $\mathrm{PhD}$ trainees who are committed to research-based careers.

What degree of autonomy is encouraged in the training program? Are trainees supported in their desire to pursue their interests? As most RiRs and PSTPs encourage autonomy and emphasize individualized training based on the trainee's goals, it is critical for each trainee to articulate his/her goals early on. To maximize flexibility, some PSTPs do not require applicants to commit to a subspecialty up front and also allow trainees the freedom to change subspecialties.

We recognize that residency is our time for ourmost significant clinical training. How are programs assuring we receivecontinuous and full clinical training while still providing research opportunities? Most programs recognize the need for and benefit of clinicalimmersion during residency, especially during a two-year, fast-trackinternalmedicineresidency. During the research phase following residency, specialty and subspecialty boards typically require trainees to maintain approximately $20 \%$ clinical effort to ensure preservation of clinical competency. 
Table 2. Recent initiatives supporting postgraduate physician-scientist training

\begin{tabular}{|c|c|c|}
\hline Initiative & Members & Charge \\
\hline AAIM RiR/PSTP Directors Annual Workshop & $\begin{array}{l}\text { RiR, PSTP Directors, and Vice-Chairs } \\
\text { for Research }\end{array}$ & Community building and share best practices \\
\hline $\begin{array}{l}\text { AAIM Physician-Scientist Postgraduate Training } \\
\text { Subcommittee }\end{array}$ & RiR and PSTP Directors & $\begin{array}{l}\text { Foster development of physician-scientist programs and } \\
\text { plan annual workshop }\end{array}$ \\
\hline AAIM RiR/PSTP Online Resources & RiR, PSTP, and MD/PhD Directors & $\begin{array}{l}\text { Message board, LISTSERV, chatroom; connecting } \\
\text { directors, community building, sharing best practices }\end{array}$ \\
\hline $\begin{array}{l}\text { APSA-Sponsored Research Pathway Directors } \\
\text { Annual Meeting (in conjunction with ASCI/AAP/ } \\
\text { APSA Annual Meeting) }\end{array}$ & $\begin{array}{c}\text { APSA Leadership } \\
\text { MD/PhD Students } \\
\text { RiR and PSTP Directors }\end{array}$ & $\begin{array}{l}\text { Inform, educate, and enhance trainee knowledge of } \\
\text { postgraduate training opportunities for physician- } \\
\text { scientists }\end{array}$ \\
\hline $\begin{array}{l}\text { AAMC Committee for Creating a Physician- } \\
\text { Scientist Training Home Project }\end{array}$ & $\begin{array}{l}\text { Deans, RiR, PSTP, and MD/PhD } \\
\text { Directors }\end{array}$ & $\begin{array}{l}\text { Define key qualities, features, and characteristics of } \\
\text { physician-scientist institutional support programs }\end{array}$ \\
\hline MD/PhD Annual Conference & $\begin{array}{c}\text { MD/PhD Trainees, Program Directors, } \\
\text { PSTP Directors }\end{array}$ & $\begin{array}{l}\text { Scientific discussion, networking, recruitment, sharing } \\
\text { best practices }\end{array}$ \\
\hline $\begin{array}{l}\text { Burroughs Welcome Fund Physician-Scientist } \\
\text { Institutional Program }\end{array}$ & & $\begin{array}{l}\text { Funding opportunity for MD only trainees with basic } \\
\text { science research interests; } 5 \text { initial awards }\end{array}$ \\
\hline
\end{tabular}

Given the trend of combined residency and fellowship integrated programs (PSTP), what efforts or practices are established to help retain trainees at their respective programs? Retention is relevant at two levels: during the residency-to-fellowship transition and the fellowship-to-faculty transition. Many PSTPs offer a letter of intent for subspecialty fellowships of interest. RiRs (by definition) and PSTPs that do not offer letters of intent for fellowship should provide mentorship and other support to maximize trainee success in their next career stage. With regard to fellowship-to-faculty transitions, PSTPs are becoming fertile ground for the cultivation of future tenure-track faculty members, and many research-intensive institutions have a track record of promoting their PSTP trainees to tenure-track faculty positions.

\section{The way forward}

Based on the urgent need to secure the leaky physician-scientist pipeline, we propose the following areas of emphasis. First, the landscape of physician-scientist training must undergo in-depth evaluation for common patterns and variations across institutions. Second, considering the relative lack of outcomes data except for the UCLA STAR Program (5), institution-specific information must be disseminated to a central database, in an anonymized fashion if necessary. Third, research track directors should communicate and share details on systems, practices, opportunities, and challenges using online communities and face-to-face meetings. Underscoring this premise was a brief survey of RiR and PSTP directors that uncovered a lack of fundamental clarity among institutions on what defines "postgraduate" physician-scientist training. Fourth, vibrant transgenerational interactions among research track directors, postgraduate trainees, $\mathrm{MD} / \mathrm{PhD}$ students, and departmental leadership should be encouraged. This should include better connectivity between $\mathrm{MD} / \mathrm{PhD}$, PSTP, and RiR trainees and regular interactions among the leadership of the respective programs at institutional and national levels. Finally, interactions among research track directors and leadership of the ABIM, Accreditation Council for Graduate Medical Education (ACGME), NIH, HHMI, Burroughs-Wellcome, and other private foundations, should be pursued. Toward these goals, there is escalating enthusiasm for organizing postgraduate physician-scientist communities from within AAIM, APSA, ASCI, and the Association of American Medical Colleges (AAMC) (Table 2). The AAIM Research Committee has also created a subcommittee on postgraduate research training to explore ways to increase support for RiR and PSTP training programs, develop and manage an online discussion forum, convene an annual Research Pathways Directors Workshop, and explore the development of a database that tracks outcomes. 


\section{Conclusion}

There has never been a more exciting time to pursue a research-based career in academic medicine. The possibilities for making scientific discoveries that improve patient outcomes are unprecedented. Through RiRs and PSTPs, research-intensive medical centers are identifying ways to streamline physician-scientist training and fostering the development of trainees into investigators who are highly sought after for tenure-track faculty positions. As the academic medical community continues to optimize RiRs and PSTPs and develop new paradigms to expand the physician-scientist pool, opportunities for individuals motivated to pursue a physician-scientist career path will only continue to grow. Finally, it is important to convey to aspiring physician-scientists that academic medical centers value and support them - this is a buyer's market full of opportunity for trainees who are motivated to pursue this career path.

\section{Acknowledgments}

This article represents a joint perspective from the AAIM Research Committee (Dr. Robert Salata, Chair and Dr. Mone Zaidi, Vice Chair), AAIM Postgraduate Research Training Subcommittee (Dr. Christopher Williams, Chair and Drs. Rebecca Baron and Olujimi Ajijola, Co-Vice Chairs), APM (Dr. Mark Geraci, Chair of the Program Committee), APDIM (Dr. Melvin Blanchard, President), APSA (Audra Iness, President, Drs. Alexander Adami, Past President and Jeremie M. Lever, Events Committee Co-Chair). We thank Dr. Neil Aggarwal at the National Heart, Lung, and Blood Institute for suggestions, input, and participation in the AAIM 2018 RiR/PSTP Directors Workshop, and Dr. Nancy Brown (APM President) for her constructive critique. The authors also express gratitude to the AAIM President, Dr. Craig Brater, and to AAIM staff, namely Margaret Breida, Michael Kisielewski, Valerie O, and Gwen Pegram for their efforts in moving the various initiatives.

Address correspondence to: Christopher S. Williams, Vanderbilt University School of Medicine, 116121 st Ave South, Nashville, Tennessee 37221, USA. Phone: 615.322.3642; Email: christopher.s.williams@vanderbilt. edu. Or to: Mone Zaidi, Icahn School of Medicine at Mount Sinai, Box 1055, Endocrinology, One Gustave L. Levy Place, New York, New York 10029, USA. Phone: 212.241.8797; Email: mone.zaidi@mssm.edu.

1. Milewicz DM, Lorenz RG, Dermody TS, Brass LF, National Association of MD-PhD Programs Executive Committee. Rescuing the physician-scientist workforce: the time for action is now. J Clin Invest. 2015;125(10):3742-3747.

2. Report from National Institutes of Health Physician-Scientists Workforce. National Institutes of Health. https://acd.od.nih gov/documents/reports/PSW_Report_ACD_06042014.pdf. Accessed November 12, 2018.

3. Todd RF, et al. Career outcomes of the graduates of the American Board of Internal Medicine Research Pathway, $1995-2007$. Acad Med. 2013;88(11):1747-1753.

4. Salata RA, et al. U.S. physician-scientist workforce in the 21st century: Recommendations to attract and sustain the pipeline. Acad Med. 2018;93(4):565-573.

5. Wong MD, Guerrero L, Sallam T, Frank JS, Fogelman AM, Demer LL. Outcomes of a novel training program for physician-scientists: Integrating graduate degree training with specialty fellowship. J Grad Med Educ. 2016;8(1):85-90.

6. Baiocchi RA, Alinari L, Grever M, Brown NJ, Klotman ME, Zaidi M. How research residencies can expand and sustain the physician-scientist workforce: "best ideas" from a special session of the 2016 APM Winter meeting. Academic Internal Medicine Insight. 2017;15(1):6-7. https://www.im.org/viewdocument/volume-15-issue-1-insight-2017.

7. Blanchard M, et al. Best practices for physician-scientist training programs: Recommendations from the Alliance for Academic Internal Medicine. Am J Med. 2018;131(5):578-584. 